\title{
Value Construction of Xinjiang Folk Sports Culture in School Physical Education
}

\author{
Zhao Zhang \\ Department of Physical Education and Research \\ Xinjiang University \\ Urumqi, Xinjiang, 830046
}

\begin{abstract}
The article uses the literature material method and expert interview method to analyze the value construction of Xinjiang folk sports culture in school physical education. It is mainly concluded that Xinjiang folk sports culture runs a long history, is rich in content and forms, and unique. At the same time, it has the value of education and physical fitness in school physical education, the value of enriching physical education curriculum resources and the value of promoting competitive sports in school. It is suggested to make full use of Xinjiang folk sports culture scientifically, reasonably sort, process, classify and transform these sports, so as to provide reference for the reform and development of school physical education, and inherit and carry forward the folk sports culture in Xinjiang.
\end{abstract}

Keywords-Xinjiang; folk sports; school

\section{INTRODUCTION}

The folk sports culture of Xinjiang is rich in content. The form of expression has its own characteristics. These sports have the function of entertainment and leisure, training body and mind, and education. The author collected and consulted literatures and monographs to study the current development situation of physical education in school. The author found that the folk sports culture of Xinjiang, some classic and easy sports for fitness and entertainment didn't play their due role. Especially the regional folk sports culture of Xinjiang lacks close interactive relationship with school physical education. The author interviewed experts of the Sports Bureau of Xinjiang Autonomous Region, experts of Ethnic Affairs Commission of Xinjiang Autonomous Region, physical education teachers of schools in Xinjiang, and ethnic students at school, and found that a few of schools have integrated some folk sports in their physical education in Xinjiang, and most of students at school, especially minority students love these folk sports very much, especially game items. Students are familiar with their ethnic folk sports and culture. Through the interview, we can see that the folk sports culture in Xinjiang has a close relationship with the school physical education. To inherit the achievements of human civilization is to inherit culture. The most effective way is education, for school education is the best, the most direct, and the most effective platform. Therefore, it is very timely and necessary to discuss the value of Xinjiang folk sports culture in school physical education, which has the practical significance and

Fund Project: National Social Science Foundation of China (15BTY084), Social Science Planning Project of Xinjiang Uygur Autonomous Region (2015BTY097); Autonomous Region Arts Base Bidding Project of Xinjiang Normal University (XJEDU040612B03). value of the times.

\section{RESEARCH METHODS}

\section{A. The Literature Material Method}

The author collected related literature from CNKI, books and network data, referred to related disciplines and works of sports science, ethnology, history and sociology, and classified and summarized relevant literatures, and found the research status, development direction, trend and shortcomings of Xinjiang folk sports culture and school physical education, and thus found suitable theoretical study observation points for the research direction and focus of the paper.

\section{B. The Interview Method}

The author interviewed experts of the Sports Bureau of Xinjiang Autonomous Region, experts of Ethnic Affairs Commission of Xinjiang Autonomous Region, physical education teachers and students in Xinjiang, and exchanged with them.

\section{The Mathematical Statistics Method}

The author made a statistical analysis on consulted and collected data by using statistics and related statistical software.

\section{RESEARCH RESULTS AND ANALYSIS}

\section{A. Analysis on the Current Situation of the Folk Sports Culture in Xinjiang}

1) The concept of folk sports: folk sports are widely spread among the people, with a distinctive local ethnic style and regional characteristics. The forms and contents of these sports are traditional. The folk sports culture of Xinjiang is various in forms and types, and rich in content. And they are not subject to the limit of time, place and equipment.

2) The development status of folk sports culture in Xinjiang: Xinjiang folk sports culture is long spread among the various nationalities in Xinjiang area. With fitness and entertainment activities as basic means, these activity modes can promote the development of physical and mental health. The folk sports culture of Xinjiang, and their origins and activity modes are basically similar among each nationality. However, due to special geographical environment of each nationality in 
Xinjiang, different religions, history, culture, economic life and folk customs, the folk sports culture of Xinjiang is rich in contents and various in connotations. The origin and development of Xinjiang folk sports are closely related to the production and life, folk culture, military war, festival and sacrifice, and so on. In the long history of the national culture, the folk sports culture of Xinjiang is deeply influenced by characteristic region and specific national folk cultures. Xinjiang folk sports are unique phenomena of multi-culture. Xinjiang folk sports and culture reflect the cultural connotation of each nationality in a round way, and show the culture, economy, life and history of each nationality in Xinjiang in different periods to some extent.

By consulting the literature materials related to folk sports culture and activities in Xinjiang, the author found that there are a few all-sided profound and systematic researches on the folk sports culture of Xinjiang. Some classic sports are facing the satiation of being lost, or has been lost. How to develop characteristic folk sports culture in Xinjiang, especially to inherit the folk sports culture of Xinjiang through school culture, has become extremely important and necessary research content.

\section{B. The Value of Xinjiang Folk Sports Culture in Physical Education}

School is the leading edge of culture dissemination, the stage for cultural heritance and development, and the front to nurture and develop sports. At same time, it is the only path for school physical education to walk toward future and mainstream culture, and become standard, popular, systematic and scientific [1]. From the perspective of the development of modern school sports, most of ancient Olympic Games were reformed and innovated with school as stage. Therefore, it is a good idea to carry out Xinjiang folk sports and culture in school, especially for Xinjiang with rich and colorful folk sports culture, and unique priority conditions. By sorting, processing and transforming folk sports, students at school would love the sports of their nationality more, and are willing to participate in these sports. If students can learn some simple Xinjiang folk sports, it can relieve the shortage of sports fields and equipment in school, and encourage students to participate in physical exercise and related competitive activities positively. These sports may become important ways and means for students of all ethnic groups in Xinjiang to exercise and entertain.

1) The value of sublimating education: the folk sports culture of Xinjiang originated from the production and life of the masses. Influenced by national culture and economy of Xinjiang, most of folk sports in Xinjiang are for entertainment in content and nature. Therefore, these activity modes stress the harmony relationship among people. Meanwhile, the collective items also account for a part of Xinjiang folk sports and cultural activities. They are various in forms, and numerous in classifications, which has reflected the information symbol of ethnic culture in Xinjiang, and conveyed the emotional and historical cultural information consciousness of their ethnic groups and sports culture. So, it has a strong appeal. Students can enjoy the happiness of the sports while participating in different forms of sports. In addition, it provides a good environment to exchange feeling and establish relationship. As the symbol of their ethnic culture, the folk sports culture of Xinjiang is respected by the public. In the enjoyment of sports, students may naturally accept the baptism of national culture under the role of mental orientation, be edified by sports culture and be exercised and trained in the sense of collective honor and responsibility representing sports spirit. And their national pride and national unity and confidence will be improved and sublimated [2].

2) The value of physical fitness: an important goal and basic core of school physical education is to enhance the physical quality of students. Schools should seriously implement and strengthen the guiding ideologies of "health first", "lifelong sports" and "sunshine sports", and actively cultivate students' sports specialty [3]. Folk sports culture in Xinjiang mainly emphasizes to build body and gain long life, which is consistent with the idea of "lifelong sports" advocated by modern schools. Xinjiang folk sports are easy to learn, and barely limited by grounds and other conditions. Meanwhile, they are easy to be promoted and popularized, and most of them are relatively moderate for body. Some folk sports emphasize on health maintenance, the harmony development of man and nature, and good physical fitness function. So, it can gradually improve students' physical and mental fitness, which is completely consistent with the advocacy of modern school physical education to gain physical and mental health in happy activities.

3) The value of constructing the diversified school physical education curriculum resources: Xinjiang folk sports not only have the value of enriching national culture but also the value of fitness and entertainment. At the same time, the rich and colorful Xinjiang folk sport modes include competitive sports, sports for leisure and entertainment, and sports for health maintenance. So, it can supplement and extend the depth and breadth of the school physical education, but also enrich and improve the diversity of school physical education curriculum resources to sort and develop Xinjiang folk sports in school physical education. It is undeniable that we cannot transplant all folk sports into school physical education, for some folk sports may not suit the development space of school sports. How to transform and use these kinds of folk sports to enrich the school physical education curriculum resources, promote and improve the physical and mental health of students is our study direction [4].

- To select Xinjiang folk sports according to the core of teaching goal

Xinjiang folk sports culture is different from modern school physical education and competitive sports in content and activity mode. So, we should select folk sports in combination with the practical teaching goal of school physical education, and take teaching goal as core. So, it is very necessary to reasonably screen and optimize folk sports suitable for school physical education with the guiding philosophy of physical and mental health [5]. For example, we can select sports, such as neck tug-of-war, rod pulling, playing ball of yarn, Damuka (King Chess), swordsmen dance, jumping goat and so on. These sports are easy to learn, have low requirements for sites and equipment, and they are not 
difficult for students. With appropriate modification, they can become good teaching content and materials. However, some folk sports have high requirements for physical equality, sites and equipment, and are dangerous. They do not conform to the guiding ideology of "sunshine sports", "happy sports" and "fitness sports", and cannot be selected for school physical education, such as speed horse racing, air runner, shooting arrow on running horse (limited by site and equipment). Some sports are dangerous, such as wrestling on horse, training fiery horse, rope dancing, and shoe-shaped gold ingot shooting.

- To select Xinjiang folk sports according to actual needs

The core purpose of school physical exercise is to continuously improve, play and excavate the potential of the human body, enhance physical fitness, and promote the student body to adapt to the environment and social changes. The physical exercise and health education are the process of teaching activities with the purpose of training body and mind. Its change ways mainly are easy and acceptable for human body. Appropriately increase exercise load and some skills in the participation process. So, we should select Xinjiang folk sports with skill content and exercise intensity, and entertainment value, and make appropriate modification in necessity. For example, the folk sport of playing ball of yarn can be a good teaching content. It has strong interestingness, and great motility, and it has a good effect in improving students' running ability and reaction ability. Playing ball of yarn cal improve students' athletic ability quickly and enhance their defensive ability. The difficult degree of the game can be determined according to site, equipment and students' physical quality. The game has a certain degree of challenge. In a similar fashion, a lot of Xinjiang folk games and interesting sports can become good teaching content with appropriate modification of their game rules and equipment [6].

- To select Xinjiang folk sports according to the physical and psychological characteristics of students

Xinjiang folk sports have rich cultural connotations. But not every item is suitable for students. Therefore, we should select sports according to the geographical environment and cultural characteristics of the school. If we can make innovation and development according to students' physical and psychological characteristics, we may achieve the desired effect [7]. At same time, it must be seen that some sports are dangerous, and limited by sites and equipment and many other conditions. For example, horse racing, air runner, rope dancing and arrow shooting are not suitable for students temporarily, because they have contradiction with the value of qualityoriented education. So, we should select folk sports according to the conditions of school and students' physical and psychological characteristics.

4) The value of promoting school sports competition: The common characteristic of traditional sports and modern sports is the competitive character. Many Xinjiang folk sports have show similarity with modern competitive sports in physical quality requirement, activity mode and characteristics. For example, arrow shooting is similar with cross-bow shooting; modern wresting is similar with classic wresting. Though the names are different, but the contents are basically the same. It can broaden students' vision, improve students' athletic ability and train talents for high-level athletic team to develop some folk sports in school.

\section{CONCLUSION}

The inheritance of culture and education are an integrated mass. Modern students should have the good habit of lifelong exercise in their development road. Interest is the best teacher. Xinjiang folk sports should become an important part of school physical education. But we should select some popular and easy sports, and introduce them into the education system of school. It can carry forward the national traditional culture and help students establish the concept of lifelong exercise firmly to develop Xinjiang folk sports in school. Of course, as the treasure of Chinese national culture, the practical value of Xinjiang folk sports culture is far beyond the scope of sports culture. From the present situation and the tendency of folk sports, there are many non-mainstream cultures in their traditional sports resources. Some may hinder the development of the sports. Therefore, we should make scientific excavation and classification, and reasonable screening to discard the dross and retain the essence. We can make Xinjiang folk sports culture conform to the development of the times, and the modern concept of fitness and healthy life. Xinjiang folk sports culture will achieve a healthy, sustainable development full of national cultural connotation and social value and function in school physical education.

\section{REFERENCES}

[1] Tong Liping. Social Value of Chinese Traditional Sports. Sports History, 2011, 4: 17-18

[2] Jiang Juan, Zhao Qiuju, Huang Shujie, Yu Xiu, Zhang Qiu and Pu Yubin. Effect of Minority Traditional Sports in Construction of Characteristic Sports Schools. Shenyang Institute of Physical Education Journal, 2010, 03: 109-112.

[3] Chen Lei, Li Pengcheng. The Cultural Value and Development of Minority Sports Resources. Guizhou National Research, 2014, 6: 178181.

[4] Wu Yongzhong. The Integration of Minority Traditional Sports into School Physical Education. Guizhou Sports Science and Technology, 2010, 02: 45-46.

[5] Zhou Xiaoli, Ma Xiaoming. Study on Values of Qinghai Minority Traditional Sports from the Perspective of Harmonious Society. Qinghai National Research, 2013, 1: 162-164.

[6] Sun Weiwei, Jiang Rong. Re-thinking of Values of Sports Social Science in Culture and Education. Journal of Nanjing Sport Institute, 2008, 4: 48.

[7] Liang Rizhong. Anthropology Thinking on Inheritance of Ethnic Minority Traditional Sports in Red River Basin. Sports Science and Technology, 2010, 03: 28-31. 